\title{
A Novel Control Strategy on Multiple-Mode Application of Electric Vehicle in Distributed Photovoltaic Systems
}

\author{
Qianwen Zhong $\mathbb{D}^{1,2}$ Yize Sun $\mathbb{D}^{1}{ }^{2}$ and Lele Peng ${ }^{1}$ \\ ${ }^{1}$ School of Urban Railway Transportation, Shanghai University of Engineering Science, Shanghai 201620, China \\ ${ }^{2}$ School of Mechanical Engineering, Donghua University, Shanghai 201620, China \\ Correspondence should be addressed to Yize Sun; sunyz@dhu.edu.cn
}

Received 21 November 2017; Revised 14 March 2018; Accepted 3 May 2018; Published 11 July 2018

Academic Editor: Tiago Pinto

Copyright ( 2018 Qianwen Zhong et al. This is an open access article distributed under the Creative Commons Attribution License, which permits unrestricted use, distribution, and reproduction in any medium, provided the original work is properly cited.

Considering the booming development of electric vehicle (EV), this article presents a novel control scheme analyzing EV multiplemode application in a number of distributed photovoltaic (PV) systems, which rationalizes the energy flow among the energy system participants containing a power grid, a grid-connected PV system, power consumption devices, storage batteries, and EV. Based on the control scheme, the authors propose two day-ahead optimal control strategies with different objective functions: one is minimizing the daily electricity expense of an individual distributed PV system and the other is minimizing the daily total expense of distributed PV systems which EV can be connected to. The model has been verified by the actual data and forecast data, respectively. The results show under the individual objective, in the distributed PV system with EV, the electricity expense can obtain an annual reduction of $27.18 \%$. Furthermore, in the distributed PV system with a storage battery as well as $\mathrm{EV}$, the electricity expense can obtain an annual reduction from $30.67 \%$ to $81.49 \%$ with a storage battery capacity changing from $1 \mathrm{kWh}$ to $20 \mathrm{kWh}$. Under the total objective, the total expense and even the individual expense have different degrees of reduction. However, the specific benefits should be rerationally distributed by balancing the interests of all the distributed PV systems. In addition, besides the application in the distributed PV systems, this model may have some potential on the development of a regional energy system.

\section{Introduction}

Due to electric vehicles (EVs) in the past several years showing an explosive development, researchers have found that these mobile distributed storage units have great potential in energy systems in future power grids, especially when coordinated with renewable energy. Therefore, the literature on the rational planning, optimal operation of EVs, and renewable energy sources has mushroomed these years. $\mathrm{Wu}$ et al. [1] briefly analyze the possible scenarios of using renewable energy to charge EVs. Chen and Duan [2] deal with the daily EV mileage uncertainty by Monte Carlo simulation and design an optimization and integration method of EV in microgrids with minimizing the total cost of electricity as the goal. ElNozahy et al. [3] also use Monte Carlo simulation to provide a probabilistic planning and scheduling method for an energy storage system integrating EVs and photovoltaic (PV) arrays in a distributed power grid. Guo et al. [4] discuss a two-stage renewable energy generation parking lot economy framework for EVs. The first stage processes uncertainty of renewable energy, and the second stage controls EV charging operation based on a predictive model. Considering the smart grid with EV and PV power generation in an islanding operation mode, Tang et al. [5] provide an online reinforcement learning method called object representation adaptive dynamic programming, which is for the adaptive islanding control unit in smart grids. Hashemi et al. [6] present a sensitivity analysis on feasibility of users supplying energy into power grids, to determine the minimum storage system capacity with different positions of low voltage power grid configuration. It prevents the overvoltage caused by PV high penetration, which presents a definition named residual power curve (RPC). Paterakis et al. [7] give a detailed family energy management system structure to determine the best home appliance scheduling strategy based on demand response on the following day when the price changes and 
power peak limits. Kaschub et al. [8] discuss the impact of different incentives and tariffs on PV storage systems in Germany. Cao [9] compares situations of integrated renewable energy to support the construction of the system with the hydrogen energy vehicles and EVs, respectively, through the reasonable control, which provides a better reference for the implementation of EU's 2050 line integration of renewable energy vehicles. Kampezidou et al. [10] compare the economic effects of two types of energy storage systems including EVs and pumped storage on high-penetration renewable energy systems. Assuncao et al. [11] present a technical and economic evaluation model for the simulation of EV battery, which is for the mismatch between demand and PV power generation and guidance of economic policy. Marra et al. [12] propose an energy storage strategy to reduce voltage rise of PV feeders by coordinating the load of EVs as an energy storage mode. An intelligent charging and discharging random scheduling method is proposed by Honarmand et al. [13], which is for a large number of EVs in a parking lot. Meanwhile, they design a self-scheduling model considering PV power generation system and distributed generators in the intelligent parking lot. For the traditional industrial microgrid, Derakhshandeh et al. [14] put forward a kind of electricity and thermal power generation scheduling coordination method, which considers the microgrid characteristics of traditional industry, also with the application of EVs, PV systems, and PV energy storage systems. Howlader et al. [15] focus on the optimal operation scheme of the smart grid with conventional thermal generators and distributed generation. To solve the optimal scheduling problem for hybrid energy microgrid including $\mathrm{PV}$, wind power generation, heat and power cogeneration, energy storage systems, and EV, Liu et al. [16] present an optimal scheduling model considering demand response, with minimum total operation cost which includes the cost of natural gas, the cost of power grid and EV charging, and the discharging cost. In the study of Ju et al. [17], wind power, PV power generation, EV, and conventional power plants are combined into a virtual power plant; considering the uncertainty and demand response, they give a two-way stochastic optimal scheduling model for the virtual plant. On that basis, they further improve the original optimization scheduling model [18] by minimizing the cost, minimizing the energy consumption, and maximizing the profit. Similarly, Coelho et al. [19] design a multiobjective power dispatch model to minimize the total cost of the microgrid of EVs, battery, maximum peak load, extreme difference, and double Sharpe ratio index, and the problem is formulated as a mixed-integer linear programming problem. Jaramillo and Weidlich [20] also propose a multiobjective microgrid optimal scheduling model; besides operating costs and peak power costs, environmental indicators are also taken into account. Gao et al. [21] start from the comfort and economy of the home users and divide the load into three categories: fixed, shiftable, and adjustable loads, and then optimize the scheduling of the home energy system according to different kinds of load. Zhao et al. [22] from residential customers' and public utilities' views build an integrated demand response simulation optimization framework for high penetration of EVs, PV, and energy storage systems under scenarios of TOU price, real-time price, and curtailment price mechanism. Based on the actual operation of dynamic optimization, Bracco et al. [23] establish an intelligent multipower and sustainable building microgrid test platform with the goal of minimizing cost and $\mathrm{CO}_{2}$ emissions at the University of Genova, Savona University Campus, and experiments show that reasonable scheduling optimization is feasible and effective.

The above lists the literature that considers the optimal dispatching control of EVs. However, as the research topic is still in its infancy, the specific criteria have not yet been determined. Most of the current studies are based on large-scale or medium-scale renewable energy power stations, so there are still a lot of problems that need to be solved or improved for distributed PV systems. Besides the above problems, there are few studies considering the multiple modes of EV which contain the application of G2V, V2G, off-grid, and driving modes as well as testing them in multiple locations.

The arrangement of this article is as follows: firstly, in Section 2, the models of each participant in the distributed PV system are illustrated. Secondly, the novel day-ahead control strategies are presented in Section 3 with different objective functions: one is minimizing the daily electricity expense of an individual distributed PV system and the other is minimizing the daily total expense of distributed PV systems which EV can be connected to. Thirdly, to verify the effectiveness of optimal control strategies, the actual data of PV generation and electricity demand are used first. Then, the results are also calculated using forecast data which could be used to discuss the feasibility under forecasting models. Finally, the conclusions are summarized and future work is briefly introduced.

\section{Distributed PV System Model}

A commonly distributed system involves the power grid, the PV system, and the storage system. In this article, due to the explosive development of EV, the authors take the EV with vehicle-to-grid (V2G) function into consideration. To simplify the model, a storage battery is used as a representative of the storage system. The most important role of batteries equipped in the distributed PV system is through charging or discharging energy to improve the stability and economy of the energy system, and contrary to the EV's battery, it can be seen as a fixed storage system. The first application of EV battery must satisfy the normal function of EV as a transport. On this basis, it can more be used as an auxiliary storage system participating in the energy adjustment of a distributed PV system. To better distinguish the fixed battery, here, it is seen as a mobile storage system. In the following, a model of each participant in the distributed PV system is introduced or built, which is required in the optimal scheduling control strategy.

2.1. PV Prediction Model. The PV array power output model is selected from $[24,25]$ :

$$
E_{\mathrm{PV}}=f\left(V_{\mathrm{OC}}, I_{\mathrm{SC}}, V_{\mathrm{M}}, I_{\mathrm{M}}, N, N_{\mathrm{s}}, N_{\mathrm{p}}, G, \text { Temp }, t_{\mathrm{in}}\right),
$$


where $V_{\mathrm{OC}}$ is the open-circuit voltage, $I_{\mathrm{SC}}$ is the short-circuit current, $V_{\mathrm{M}}$ is the voltage at maximum power point, $I_{\mathrm{M}}$ is the current at maximum power point, $N$ is the serial number of PV cells in one panel, $N_{s}$ is the serial number of PV array, $N_{\mathrm{p}}$ is the parallel number of PV array, $G$ represents the solar irradiance, Temp represents the temperature, and $t_{\text {in }}$ represents the time interval of the recorded data.

As there must be the difference between the PV model built with parameters from the manufacturer and data recorded in the actual outside environment and the error information of the historical data is missing in this paper, here in this model, the authors assumed that the error of PV power generation forecasting model is consistent with the Gaussian distribution,

$$
\mathrm{Er}_{\mathrm{PV}}=\frac{\left|E_{\mathrm{PV}}-\widehat{E_{\mathrm{PV}}}\right|}{E_{\mathrm{PV}}} \sim N(\mu, \sigma) .
$$

In the above equation, $\mathrm{Er}_{\mathrm{PV}}$ represents the error between the $\mathrm{PV}$ forecasting value $\widehat{E_{\mathrm{PV}}}$ and the actual generation $E_{\mathrm{PV}}$. Through setting the mean error $\mu$ and mean square deviation $\sigma$, the PV power generation forecasting values are randomly generated under different conditions by MATLAB software.

2.2. Electricity Load Forecast Model. A Bayesian neural network (BNN) model is established to forecast the load values with 16 load-related inputs. The vectors of inputs, $\mathbf{V}_{I}$, are shown:

$$
\begin{aligned}
\mathbf{V}_{I}= & {\left[\mathbf{t}, \mathbf{d}_{\mathbf{t}}, \mathbf{T}, \mathbf{T}_{n-1}, \mathbf{T}_{n-2}, \mathbf{R H}, \mathbf{R H}_{n-1}, \mathbf{R H}_{n-2}, \mathbf{L}_{n-1}, \mathbf{L}_{n-2},\right.} \\
& \cdot \mathbf{L}_{n-3}, \mathbf{L}_{n-4}, \mathbf{L}_{n-\left(24 / t_{i}\right)}, \mathbf{L}_{n-\left(24 / t_{i}\right) \cdot 2}, \mathbf{L}_{n-\left(24 / t_{i}\right) \cdot 7}, \mathbf{L}_{\left.n-\left(24 / t_{i}\right) \cdot 7 \cdot 2\right]}
\end{aligned}
$$

To build the electricity demand forecast model, the input factors which are mostly considered in the existing models would be the time type and the meteorological type. Based on the similar consideration, in this article, time of every day, $\mathbf{t}$; day type (which is defined as integers from 1 to 7 to express Monday to Sunday, resp., and 8 to express special holidays), $\mathbf{d}_{\mathrm{t}}$; ambient temperature, $\mathbf{T}$; and relative humidity, $\mathbf{R H}$, are firstly considered as the inputs. $n$ is used to represent the series order number of historical sample data's intervals. For instance, $\mathbf{T}_{n-1}$ means the temperature vector observed from one interval before the $n$ interval, which is actually the data from the previous interval. Due to no record before the historical first interval, here $T_{1}$ is used as the initial value to complement the vector. If other vectors lack some items, the same complement method is used. Besides these vectors, historical load data, $\mathbf{L}$, are also used in inputs to increase the accuracy of the forecast model. With a similar meaning of subscript, the eight historical data vectors in the latter half are actual load in the first past interval, the second past interval, the third past interval, the fourth past interval, the same interval of yesterday, the same interval of the day before yesterday, the same interval in last week with the same day type, and the same interval in the week before last week with the same day type, respectively. These eight inputs of the forecast model basically cover the most relevant historical load values within the past two weeks.

2.3. Storage Battery Model. The control algorithm of the storage battery is designed by geometrical-logical control method in another published article of the authors [26]. The key point of this algorithm can be described as follows. Under a time-of-use (TOU) electricity retail tariff, if it satisfies the condition that the tariff is always higher than the feed-intariff (FiT) even considering the inefficiencies of energy transformation, ignoring initial capital and maintenance costs of storage battery system, the best size of the battery should equal the sum of the positive values obtained by the load minus the PV generation in every interval within the shoulder and peak time. When the maximum available storage energy of a battery is less than the optimum size but is larger than the surplus PV energy, the controller will fully charge the battery before the peak time. If the available energy of a battery at one day's beginning is less than the surplus PV energy, the beginning capacity should be used firstly during the morning shoulder shortfall, then the rest should be discharged completely during the morning off-peak time, in order to make the battery empty in preparation for the following period of surplus PV generation.

Besides the above control algorithm of storage batteries, the following (4), (5), and (6) are the assumption or basic limitation on the storage batteries which must be satisfied:

$$
\begin{aligned}
& E_{\mathrm{B}}=E_{\mathrm{B}_{+}}-E_{\mathrm{B}_{-}} \text {, } \\
& 0 \leq E_{\mathrm{B}_{+}} \leq P_{\mathrm{B}_{\text {maxcharge }}} \cdot t_{\text {in }}, \\
& 0 \leq E_{\mathrm{B}_{-}} \leq P_{\mathrm{B}_{\text {max }} \text { discharge }} \cdot t_{\text {in }}, \\
& -P_{\mathrm{B}_{\text {max discharge }}} \cdot t_{\text {in }} \leq E_{\mathrm{B}} \leq P_{\mathrm{B}_{\text {max }} \text { charge }} \cdot t_{\text {in }} \text {, } \\
& E_{\mathrm{B}_{\text {size }}} \cdot \mathrm{SoC}_{\mathrm{B}_{\text {min }}} \leq E_{\mathrm{B}_{0}}+\left(E_{\mathrm{B}}-E_{\mathrm{B}_{\text {loss }}}\right) \leq E_{\mathrm{B}_{\text {size }}} \cdot \mathrm{SoC}_{\mathrm{B}_{\max }} \text {, }
\end{aligned}
$$

where $E_{\mathrm{B}}$ is the energy change of battery. When this parameter is positive, it means the battery has been charged during that period; on the opposite, when it is negative, it means the battery has been discharged during that time. To better distinguish the charging and discharging energy, the authors define two parameters, $E_{\mathrm{B}_{+}}$and $E_{\mathrm{B}_{-}}$, respectively, to represent them, which are limited to greater or equal to 0 and at the same time only one can be greater than 0 . If $E_{\mathrm{B}}$ is negative, the battery is discharged and helping to meet the load. Equation (5) gives the limitations of the battery. In order to extend the life of the battery, manufacturers commonly recommend the optimal and the maximum charging and discharging power rates. $P_{\mathrm{B}_{\text {max }} \text { charge }}$ and $P_{\mathrm{B}_{\text {max }} \text { discharge }}$ represent the maximum charging and discharging rates of the battery, based on manufacturer recommendations. Under this case, the constraints of the battery are two inequalities limiting the bidirectional energy flow of the battery. Equation (6) further limits the battery's state of charge (SoC) between the lower bound and upper bound if needed. It should be noticed that here the energy change of all the ordered periods from the initial time 
interval to the current time interval is accumulated because the SoC must satisfy this constraint in every moment during the entire optimization duration. In this equation, $E_{\mathrm{B}_{\text {size }}}$ is the specified capacity of the storage battery. $E_{\mathrm{B}_{0}}$ represents the initial battery energy. SoC $_{B_{\text {min }}}$ and $S_{0} C_{B_{\max }}$ are the minimum and maximum SoC of the battery, respectively. $E_{\mathrm{B}_{\text {loss }}}$ is the energy loss of the battery, mostly resulting from heat loss.

It is worth noting that all the parameters used to explain the values related to direction in the model in this article are nonnegative values. For the following illustration, a parameter named $B_{\max }$ is also given here to represent the maximum energy that could be used in the storage battery when it is fully charged, which is also mentioned and applied in the geometrical logical analysis battery control algorithm.

2.4. EV Battery Model. Similar to the storage battery models, here the following equations of the EV battery can be obtained:

$$
\begin{aligned}
& E_{\mathrm{EV}}=E_{\mathrm{EV}_{+}}-E_{\mathrm{EV}_{-}}, \\
& 0 \leq E_{\mathrm{EV}_{+}} \leq E_{\mathrm{EV}_{\text {max }} \text { charge }} \cdot t_{\mathrm{in}}, \\
& 0 \leq E_{\mathrm{EV}_{-}} \leq E_{\mathrm{EV}_{\text {max }} \text { discharge }} \cdot t_{\mathrm{in}}, \\
&-P_{\mathrm{EV}_{\text {max }} \text { discharge }} \cdot t_{\text {in }} \leq E_{\mathrm{EV}} \leq P_{\mathrm{EV}_{\text {max }} \text { charge }} \cdot t_{\text {in }}, \\
& E_{\mathrm{EV}_{\text {size }}} \cdot \mathrm{SoC}_{\mathrm{EV}_{\text {min }}} \leq E_{\mathrm{EV}_{0}}+\left(E_{\mathrm{EV}}-E_{\mathrm{EV}_{\text {loss }}}-E_{\text {trip }}\right) \\
& \leq E_{\mathrm{EV}_{\text {size }}} \cdot \operatorname{SoC}_{\mathrm{EV}_{\text {max }}},
\end{aligned}
$$

where $E_{\mathrm{EV}}$ is the energy change of the EV battery. When this parameter is positive, it means the EV battery has been charged during the duration. If this value is negative, the EV battery has been discharged and helping to meet the load. $E_{\mathrm{EV}_{+}}$is the energy change in $\mathrm{G} 2 \mathrm{~V}$ mode. $E_{\mathrm{EV}_{-}}$is the energy export in V2G mode. Equation (7) gives the energy usage of the EV battery. $P_{\mathrm{EV}_{\text {max }} \text { charge }}$ and $P_{\mathrm{EV}_{\text {max }_{\text {discharge }}}}$ represent the maximum charging and discharging rate of the EV battery, respectively, based on manufacturer recommendations. Equation (9) limits the SoC of the EV battery between the lower bound and upper bound. $E_{\mathrm{EV}_{\text {size }}}$ is the specific size of the $\mathrm{EV}$ battery. $E_{\mathrm{EV}_{0}}$ represents the initial battery energy. SoC $\mathrm{EV}_{\text {min }}$ and $\mathrm{SoC}_{\mathrm{EV}_{\max }}$ are the minimum and maximum SoC values of the EV battery, respectively. $E_{\mathrm{EV}_{\text {loss }}}$ is the energy loss of the EV battery, mostly resulting from heat loss. $E_{\text {trip }}$ represents the energy consumed when the EV is driving on a certain trip between two known locations within some time. Subscripts are used to distinguish the different trips between locations if necessary, for example, $E_{\text {trip }}$ represents the energy consumption of the EV battery between location $a$ and location $b$.

Due to the objective in this article which is to obtain the minimum electricity expenses, the bill reductions should compare with the V2G cost of the EV. In [27], this cost can be calculated by the following:

$$
C_{\mathrm{a}}=E_{\mathrm{V} 2 \mathrm{G}} \cdot N_{\mathrm{d}} \cdot\left(C_{\mathrm{d}}+r_{\mathrm{e}}\right) .
$$

This equation is used to determine the cost to the EV owner for allowing access to the stored energy in their vehicles, where $C_{\mathrm{a}}$ is the annual cost. $E_{\mathrm{V} 2 \mathrm{G}}$ is the energy available in each EV per dispatch in kWh. $N_{\mathrm{d}}$ is the number of dispatches per year. $C_{\mathrm{d}}$ is the cost of battery degradation. $r_{\mathrm{e}}$ is the electricity price.

\section{Proposed Control Strategies}

As the EV has the transport function, it can move from one location to another. In other words, when the EV is connected to the grid of some parking place, its battery can be applied as a small storage unit to that place.

A comprehensive analysis of EVs applied in the distributed PV systems can be shown in Figure 1. The box on the top left shows two scenarios of one PV system, number 1 PV system, in which the left circle is the distributed PV system with EV connected. The basic participants in one distributed PV system include power grid, grid-connected PV generation, storage battery, electricity load, and EV, which would provide or consume electric energy. The top right box illustrates the two probabilities when the EV is out of the number $1 \mathrm{PV}$ system. One is that the EV is in another distributed PV system, the other is that the EV is driving on a trip. The box on the lower left is all the given states of the distributed PV systems when the EV battery is connected to one of them, and the lower right is the state of the distributed PV system when the EV is driving on some trip from one distributed PV system to another or the EV is off-grid.

The main research content of this article is to design the optimal energy flow of distributed PV systems with EV multiple-mode application under the objective of minimizing the electricity expense. Based on the model described in the above section, the control structure of distributed PV systems can be shown in Figure 2.

It can be seen from the figure that the distributed PV system integral model includes PV generation forecast model, BNN load forecast model, control model of storage battery by geometrical logic analysis methodology, and multiple-mode optimal control of EV battery in distributed PV systems. In order to further discuss the control strategy of distributed PV systems, the above diagram describes a proposed two-level storage system control strategy based on the actual situation of the system. That means in a storage system which includes a storage battery and an EV battery, the storage battery is preferred and firstly used. The technological development at this stage makes the storage equipment still limited by a variety of factors, such as its cost, life, and efficiency, so under such condition the authors make the EV battery only as a secondary and auxiliary option for storage purpose with reasonable and practical significance. It can be found from the figure that the input parameters for the second-level storage system are the remaining surplus PV generation or electricity demand after the first-level control process of storage battery system.

A novel optimal model considering the EV-applied multiple modes can be formulated. Suppose there is an EV storage aggregator which can control the EV battery charging 

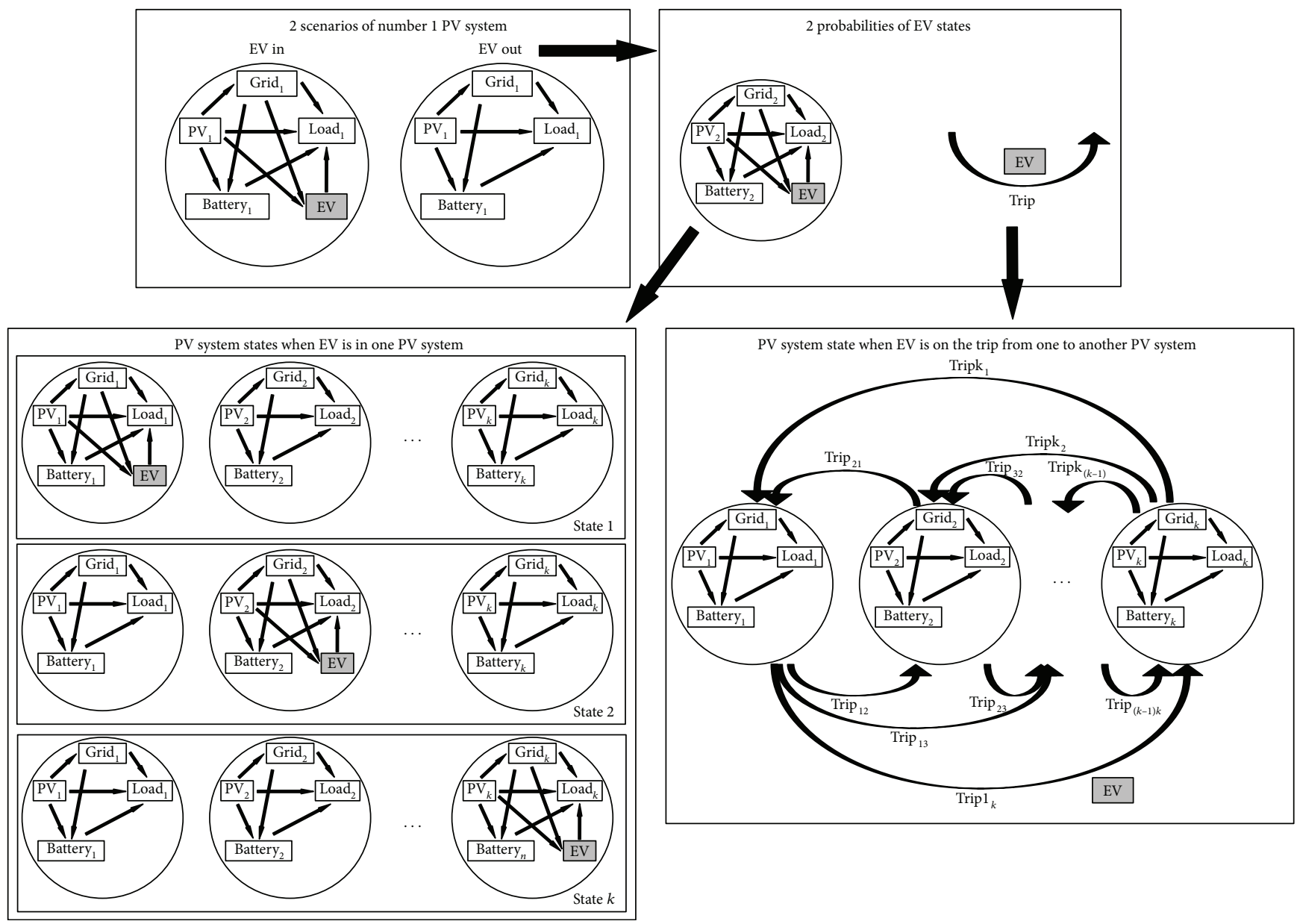

FIGURE 1: Scenarios of the distributed PV systems with EV multiple-mode application.
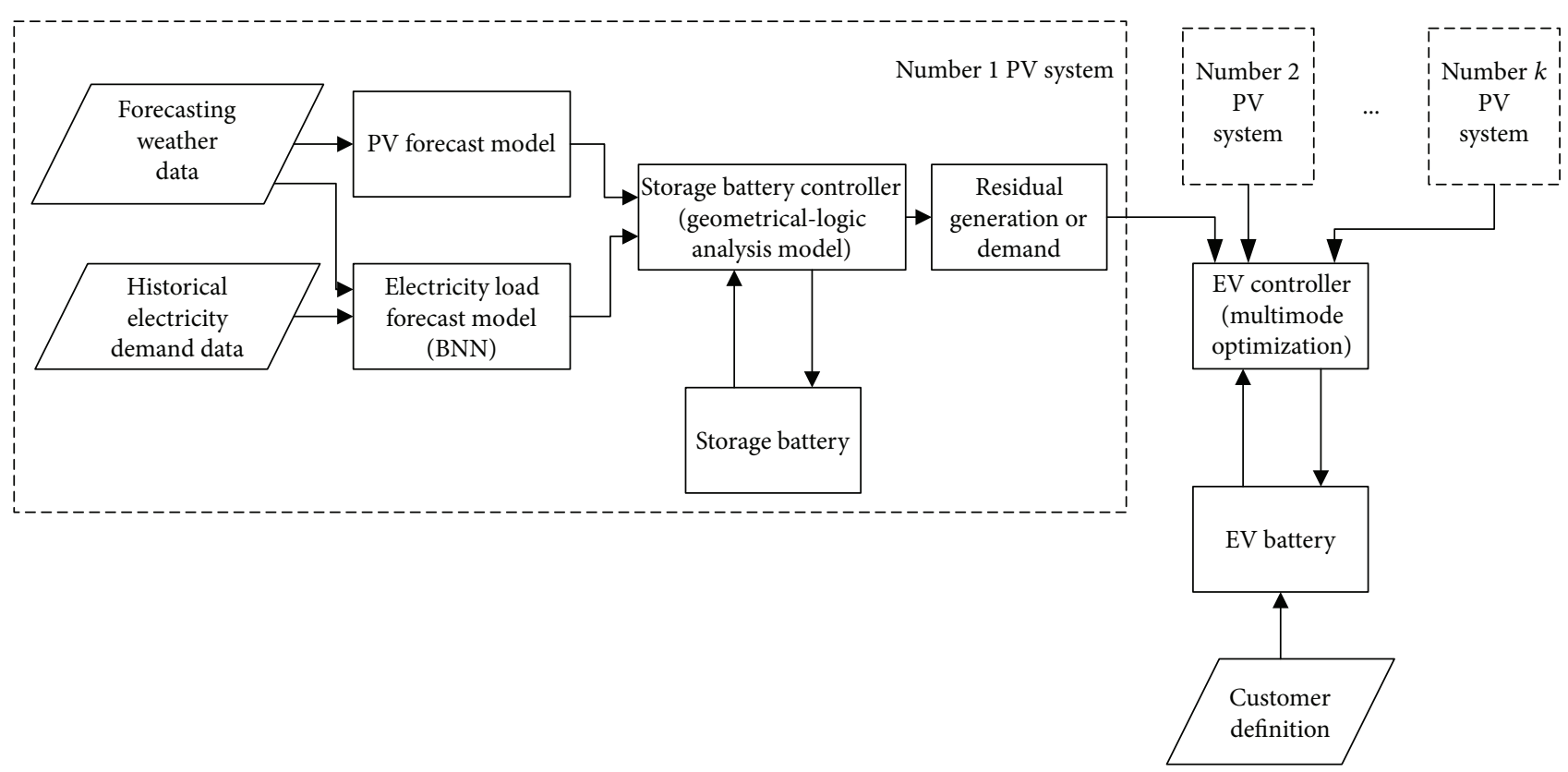

FIGURE 2: Control schematic of the distributed PV systems with EV multiple-mode application. 
and discharging schedule in all the distributed PV systems which the EV can be connected to the grid.

From the above illustration, the following equilibrium equations can be obtained. When the $\mathrm{EV}$ is in the number $i$ PV system, the EV battery is deemed as a storage device just like a battery joining the energy flow in one distributed PV system. On the contrary, other distributed PV systems do not have EV battery participating in the energy change.

$$
\begin{aligned}
& E_{\text {grid }_{i}}(t)+E_{\mathrm{PV}_{i}}(t)-E_{\mathrm{B}_{i}}(t)-E_{\text {load }_{i}}(t)-E_{\mathrm{EV}}(t)=0, \\
& E_{\text {grid }_{j}}(t)+E_{\mathrm{PV}_{j}}(t)-E_{\mathrm{B}_{j}}(t)-E_{\text {load }_{j}}(t)=0(j \in(1, k) \cap j \neq i) .
\end{aligned}
$$

In the above equation, integer $i$ represents the number $i$ of the ordered distributed PV systems in which the $\mathrm{EV}$ battery is being connected to its power grid in time $t ;(t)$ represents the corresponding value in ordered period $t$ with observation time interval $t_{\text {in }}$, and the total number of ordered periods is $n_{\mathrm{f}} ; j$ represents other ordered distributed PV systems without EV connection in time $t$, and $0<j<\mathrm{k}$ but $j \neq i$, where $k$ is the number of distributed PV systems. $E_{\text {grid }}, E_{\mathrm{PV}}, E_{\text {load }}, E_{\mathrm{B}}$, and $E_{\mathrm{EV}}$ are the energy change of the grid, PV, load, battery, and EV battery in time $t$, respectively. From an optimal economy view, in this article the proposed optimal control model has been firstly designed with an objective of minimizing electricity cost of one specific distributed PV system.

$$
\min C_{i}=\sum_{t=1}^{n_{f}}\left(M_{i}(t) \cdot E_{\text {grid }_{i_{+}}}(t)-\operatorname{FiT}(t) \cdot E_{\text {grid }_{i_{-}}}(t)\right),
$$

where $C_{i}$ represents the electricity cost of the number $i \mathrm{PV}$ system, $n_{\mathrm{f}}$ is the final time order, $M_{i}$ and FiT are the electricity retail tariff of number $i \mathrm{PV}$ system and feed-in-tariff of solar energy, respectively, and $E_{\text {grid }_{+}}$and $E_{\text {grid_ }}$ stand for the energy imported from or exported to the grid in unit interval $t_{\text {in }}$, respectively. From actual condition analysis, this objective is likely to happen when the EV owner wants to obtain the lowest electricity expense of his residence.

Another possible objective may be the minimization of the total electricity cost for all the distributed PV systems in which the EV battery may participate in.

$$
\min \quad C_{\text {total }}=\sum_{i=1}^{k} \sum_{t=1}^{n_{\mathrm{f}}}\left(M_{i}(t) \cdot E_{\text {grid }_{i_{+}}}(t)-\operatorname{FiT}(t) \cdot E_{\text {grid }_{i_{-}}}(t)\right) .
$$

The authors would like to assess, when multiple locations share one EV controller, whether the total electricity cost could be effectively reduced or not. Through the calculations under these two different objectives, the optimal scheduling problem can be analyzed and solved from different views.

The following equations are the constraints of the distributed PV system with net metering when EV is being connected to the grid: subject to $E_{\text {grid }}(t)=E_{\text {grid }_{+}}(t)-E_{\text {grid }_{-}},(t)$,

$$
\begin{aligned}
& E_{\text {grid }_{+}}(t) \leq E_{\text {load }}(t)+E_{\mathrm{B}}(t)+E_{\mathrm{EV}}(t), \\
& E_{\text {grid_ }_{-}}(t) \leq E_{\mathrm{PV}}(t) .
\end{aligned}
$$

This equation gives the limitations of electricity energy from and into the grid. When considering the energy balance, it can be found that the maximum energy import occurs when all the electrical devices simultaneously consume electricity from the grid, and the maximum energy export occurs when all the surplus PV generation is fed into the grid. When the EV is being connected to the grid, the $\mathrm{EV}$ battery is available for bidirectional interaction.

On the contrary, when the EV is out of the distributed PV system, the above equation should be

$$
\begin{aligned}
& 0 \leq E_{\text {grid }_{+}}(t) \leq E_{\text {load }}(t)+E_{\mathrm{B}}(t), \\
& 0 \leq E_{\text {grid__ }_{-}(t) \leq E_{\mathrm{PV}}(t) .}
\end{aligned}
$$

The constraints should also contain the limitations on the storage battery and EV battery.

Under this way, the total $E_{\mathrm{V} 2 \mathrm{G}}$ in this article can be expressed as

$$
E_{\mathrm{V} 2 \mathrm{G}}=\sum_{i=1}^{n_{\mathrm{f}}} E_{\text {grid }_{i_{+}}} .
$$

\section{Results and Discussion}

Here, this verification scenario of two distributed PV systems is assumed as the description in the following. During the working day, the EV owner usually should stay in his workplace, so he drives the EV from home to the workplace and parks the EV there during the working hours. The time of off-grid covering one trip is assumed as half hour. In this article, the working hours are assumed from 9:00 to 17:00. Then, after the working hours, he drives the EV home and leaves the EV connected to the charging pile during the night. That is to say under this scenario, most of time in the working days, the EV is mainly parked in the owner's home or parking area of the workplace. If in these two locations, the EV can both be connected to the grid and participate in the energy systems, the proposed optimal control strategy should effectively reduce the expense of electricity.

The following is a case as an example using a whole year historical data of number 13 in 300 households with PV users from July 1, 2010, to June 30, 2011, which is provided by Ausgrid Company, a utility in Australia [28]. The data includes the electricity load, PV size, PV generation with half-hour interval, and also postcode to express the location. The specific home is with a $2.22 \mathrm{~kW}$ PV system, and the average electricity consumption was $11.99 \mathrm{kWh}$ per day, which had a typical load shape with a small peak in the morning and a larger peak in the afternoon. The meteorological correlation parameters are from the Bureau of Meteorology, Australia. To better illustrate and design the economic control strategy, Sydney's actual three-level time of use price is chosen as a whole integrated control strategy for specific operations and result analysis, which includes off-peak time (0:00-7:00 and 
22:00-24:00), shoulder time (7:00-14:00 and 20:00-22:00). and peak time (14:00-20:00) in one day. The electricity retail tariff (which is $0.13 \$$ in off-peak time, $0.21 \$$ in shoulder time, and $0.53 \$$ in peak time) and the FiT $(0.08 \% / \mathrm{kWh})$ are both from the Independent Pricing and Regulatory Tribunal (IPART). The efficiencies of the PV system are the same as [26], which include the efficiency of DC/DC, 0.95; the efficiency of DC/AC or AC/DC, 0.95 ; the efficiency of the battery charging state, 0.85 ; and the efficiency of the battery discharging state, 0.9. In the case, EV monitoring data is provided by Smart Grid Smart City [29], which follows 20 EVs of i-MiEV type from Mitsubishi brand. They recorded the data with very detailed information of EV application, such as the parameters of time, state of charge (SoC) of the EV battery, mileage, charging time of every start and end, trip time of every start and end, and also distance, average velocity, and simple description of trip destination. In the following computation, the authors apply the average value of EV trip as the common trip features in which the average trip time is 18 minutes and the average battery consumption of one trip is $1.88 \mathrm{kWh}$ and assume that the charging efficiency is the same as discharging efficiency, which is $74.6 \%$ from the EV brochure supplied by the manufacturer. Due to the consideration of battery reasonable application, the $\mathrm{SoC}$ of the storage battery and the EV battery is controlled within $20 \% \sim 100 \%$. The actual load data used for the workplace is calculated, the average half-hour load value of the Chemical and Biomolecular Engineering Building in Sydney University in one year from Dec 1, 2007, to Nov 30, 2008. Because there is no PV system in this building and the goal of the validation is to show the effectiveness of the proposed optimal control strategy, here the second distributed PV system is simplified to energy system with power grid and load only.

The test scenario only contains two distributed systems and one EV application in a whole year; therefore, it is not a very big problem, and the authors simply chose the selfcontained function "fmincon" in MATLAB software to solve it, and in order to ensure the correctness of the solutions, we assumed the initial battery and EV battery as fully charged $\left(\mathrm{SoC}_{\mathrm{B}}(0)=100 \%\right.$ and $\left.\mathrm{SoC}_{\mathrm{EV}}(0)=100 \%\right)$. The program of the proposed control model has been run on Dell XPS13 laptop, with the Intel Core i7 and $1.9 \mathrm{GHz}$ of CPU master frequency. The average running time is around half an hour once for the whole year. The memory features after the program running are $3937 \mathrm{MB}$ of physical memory (RAM), $4963 \mathrm{MB}$ of page file (swap space), and $6990 \mathrm{MB}$ of virtual memory (address space) in use.

The results of annual electricity expense under different conditions are listed in Table 1. The different conditions include the storage battery capacity changes, with or without $\mathrm{EV}$, and the objective function changes. $B_{\max }$ as abovementioned represents the available capacity of the storage battery. The results show that if the distributed PV system only with the storage battery capacity increases from $1 \mathrm{kWh}$ to $20 \mathrm{kWh}$ and without EV application, the electricity expense can obtain a reduction from $13.44 \%$ to $58.39 \%$. If the distributed PV system with the storage battery capacity increases from $1 \mathrm{kWh}$ to $20 \mathrm{kWh}$ and with an EV application, the electricity
TABLE 1: Computing result comparison of the whole year under different conditions.

\begin{tabular}{|c|c|c|c|c|c|}
\hline \multirow{2}{*}{$\begin{array}{l}B_{\max } \\
(\mathrm{kWh})\end{array}$} & \multirow{2}{*}{$\begin{array}{c}\text { Electricity } \\
\text { expense } \\
\text { without } \\
\text { EV }(\$)\end{array}$} & \multirow{2}{*}{$\begin{array}{l}\text { Electricity } \\
\text { expense } \\
\text { reduction } \\
\text { without } \\
\text { EV (\%) }\end{array}$} & \multicolumn{2}{|c|}{$\begin{array}{l}\text { Electricity expense } \\
\text { with EV (\$) }\end{array}$} & \multirow{2}{*}{$\begin{array}{c}\text { Electricity } \\
\text { expense } \\
\text { reduction } \\
\text { under } \\
\text { objective } \\
\min \left(C_{i}\right) \\
(\%)\end{array}$} \\
\hline & & & $\min \left(C_{\text {total }}\right)$ & $\min \left(C_{i}\right)$ & \\
\hline 0 & 891.34 & 0 & 819.35 & 649.03 & 27.18 \\
\hline 1 & 771.53 & 13.44 & 727.18 & 618.00 & 30.67 \\
\hline 2 & 683.08 & 23.36 & 645.87 & 540.77 & 39.33 \\
\hline 3 & 618.34 & 30.63 & 591.47 & 476.57 & 45.97 \\
\hline 4 & 570.86 & 35.95 & 543.69 & 429.24 & 51.84 \\
\hline 5 & 536.24 & 39.84 & 510.92 & 393.86 & 55.81 \\
\hline 10 & 436.47 & 51.03 & 393.78 & 270.21 & 69.68 \\
\hline 15 & 388.23 & 56.44 & 333.45 & 201.17 & 77.43 \\
\hline 20 & 370.93 & 58.39 & 300.54 & 164.99 & 81.49 \\
\hline
\end{tabular}

expense can obtain a reduction from $30.67 \%$ to $81.49 \%$. From the table, under the condition of only with EV as a mobile storage equipment and not equipped with other storage equipment, the customer residential electricity expense could get a $27.18 \%$ saving when the objective is $\min \left(C_{i}\right)$. With the storage battery capacity increasing, electricity consumption saving values gradually increased. However, in the actual energy system design and application, the storage capacity leads to the cost increasing of storage system. Under this way, the designer must compare the saving with the cost and take the degradation, life, and other related factors of storage system into consideration to determine the reasonable storage system capacity which can generate the maximum benefit.

The results obtained above are calculated by the actual historical data of PV generation and electricity demand and mainly discuss the relevant conclusions and effectiveness of the optimization control under the designed distributed PV system control strategy in this article. While the EV battery is parking in the workplace energy system, it could play a role in shifting load. It indicates that the EV battery is charged during the lower price period and discharged in the higher price period in order to reduce the workplace electricity consumption. Under this control, the workplace applies the EV battery as a storage unit to reduce the expense on electricity, and the EV battery is charged by the workplace grid power to a certain degree. This can be seen as the application of EV, a mobile storage system, achieves a win-win situation. However, the specific benefits should be rerationally distributed by balancing the interests of all participants.

Further, the feasibility and effectiveness of the control strategy are analyzed with day-ahead predicted PV generation and demand. Due to the missing information of PV modules, here the authors assume the error of PV prediction model conforming to the Gaussian distribution which is introduced in Section 2.1, and to simplify the calculation, the average error $\mu$ is set as 0 . Since in the selected customer's 
TABLE 2: Performance of the load forecast model.

\begin{tabular}{lcc}
\hline Samples $(17520)$ & MSE & $R^{2}$ \\
\hline Training set $(10512,60 \%)$ & $3.77 e-2$ & $8.55 e-1$ \\
Validation set $(3504,20 \%)$ & 0 & 0 \\
Test set $(3504,20 \%)$ & $5.29 e-2$ & $7.85 e-1$ \\
\hline
\end{tabular}

energy system, the recorded PV generation is generally less than $1 \mathrm{kWh}$ in the recorded time interval of half an hour, the standard deviation $\sigma$ is set as 0.1 and 0.2 , respectively. To realize the above settings, the MATLAB software is chosen to generate the forecasting PV power values under our assumptions and different deviations by a function named "random."

The BNN method is introduced to establish the customer's electricity load forecasting model, which has been illustrated in Section 2.2. The data used to calculate is still from Ausgrid company as the above descriptions. The total number of samples is 17520 and is randomly divided into $60 \%$ as the training set, $20 \%$ as the validation set, and $20 \%$ as the test set by MATLAB software, respectively. The MSE and $R$-squared values of the electricity demand forecast model are shown in Table 2.

From the historical data of this chosen sample, the repeatability and regularity of the electricity consumption way are relatively weak. For this type of user, higher prediction accuracy may require the customer to provide relevant factors as detailed as possible or supply own defined schedule of electricity demand. However, it is very difficult to realize such requirements. Thus, here even the prediction performance is lower compared to some other customers' from the 300 households of Ausgrid, it roughly could be seen to meet the basic test needs.

In order to compare the designed control strategy performance using actual historical data and predicted values as inputs, respectively, the authors calculate the results of six different input conditions under the objective function $\min \left(C_{i}\right)$. The results are listed in Table $3 ; \mathbf{L}_{\mathrm{H}}$ is the historical data of load and $\mathrm{PV}_{\mathrm{H}}$ expresses the historical data of $\mathrm{PV}$ generation, respectively; $\mathbf{L}_{\mathrm{F}}$ is the forecasting data of load and $\mathrm{PV}_{\mathrm{F}}$ expresses the forecasting data of $\mathrm{PV}$, respectively. It can be seen from the table that, as discussed above, the customer's power consumption mode has a relatively weak repeatability and strong randomness and the performance with demand prediction is inferior to other cases, which leads to a bigger difference than with other inputs. When the standard deviation of the PV generation error increases, the difference between the actual and the forecasting inputs increases, which is consistent with the assumption of the model performance.

In order to compare the above results intuitively, Figure 3 illustrates the customer annual consumption varied with the increasing storage battery capacity. It is obvious that the minimum residential annual electricity expense under $\min \left(C_{i}\right)$ is lower than $\min \left(C_{\text {total }}\right)$. Under the $\min \left(C_{\text {total }}\right)$, the EV owner's residential electricity expense also significantly reduced compared to the case without EV. This indicates that EV as a mobile storage system to participate the energy conversion of multiple parking places can obtain significant economic benefits through reasonable optimal scheduling control.

From the figure, it is also evident that the increase of the storage battery capacity could reduce the difference between the actual consumption and the calculated consumption by the forecast inputs. This indicates that the storage battery has a certain role to improve the overall optimal control performance in the distributed PV system. This improvement in performance can be converted to economic benefits, so as to provide a reference when the designers consider the cost of storage system.

Through the above calculation and discussion, the error of annual electricity expense with forecast inputs is less than $10 \%$ by comparison with actual inputs. Here, the authors go a step further to discuss the control model with predicted inputs. In the following, Table 4 shows some situations to see when the model would be out of work with increasing deviation.

As the performance of the electricity demand is already known by the forecast load model, a simple way to change the predicted input is just to assume the forecasting PV generation with different $\sigma$ values. Table 4 shows the results under different assumptions with $B_{\max }=5 \mathrm{kWh}$ and $\min \left(C_{i}\right)$. Due to the PV generation values used in the computing which are almost all smaller than 1 , the assumed value range of $\sigma$ is big enough under this condition. That means when the $\sigma$ value is assumed as 0.5 , the average error will be greater than $50 \%$, and when $\sigma$ is assumed as 1.0 , the average error will be greater than $100 \%$. That is already the most extreme situation and nearly would not happen. From the results listed in the table, it can be seen that even when $\sigma$ is 0.5 , the annual electricity expense under the designed control scheme is still very close to the results obtained with the actual data. However, when $\sigma$ is 1.0 , the results are greatly deviated from the actual input operation. Thus, under this extreme condition, the control strategy is invalid. It is noteworthy that this failure situation is basically impossible to happen. Therefore, the overall scheme of the distributed systems established can meet the practical application and has notable economic benefits.

\section{Conclusion}

Considering the booming development of the electric vehicle $(\mathrm{EV})$, this article presents a novel control scheme analyzing EV multiple-mode application in a number of distributed photovoltaic (PV) systems, which rationalizes the energy flow among the energy system participants containing power grid, grid-connected PV system, power consumption devices, storage battery, and EV. In this article, the EV with V2G mode is seen as a mobile storage system, and multiple mode represents the EV that can be applied with G2V, V2G, offgrid, and driving modes and also can be used in multiple locations. In the control scheme, the PV prediction model with an error satisfying Gaussian distribution and load forecast model based on Bayesian neural network learning method are used as the inputs of the control framework. According to the inputs, the authors propose two day- 
TABLE 3: Results of annual electricity expenses under $\min \left(C_{i}\right)$ with different inputs.

\begin{tabular}{cccccccc}
\hline $\min \left(C_{i}\right)(\$)$ & $L_{\mathrm{H}} \& \mathrm{PV}_{\mathrm{H}}$ & $L_{\mathrm{F}} \& \mathrm{PV}_{\mathrm{H}}$ & $\begin{array}{c}L_{\mathrm{H}} \& \mathrm{PV}_{\mathrm{F}} \\
\sigma=0.1\end{array}$ & $\begin{array}{c}L_{\mathrm{H}} \& \mathrm{PV}_{\mathrm{F}} \\
\sigma=0.2\end{array}$ & $\begin{array}{r}L_{\mathrm{H}} \& \mathrm{PV}_{\mathrm{F}} \\
\sigma=0.1\end{array}$ & $\begin{array}{r}L_{\mathrm{H}} \& \mathrm{PV}_{\mathrm{F}} \\
\sigma=0.2\end{array}$ \\
\hline \multirow{3}{*}{$B_{\max }(\mathrm{kWh})$} & 0 & 649.03 & 583.42 & 636.96 & 611.67 & 571.56 & 547.15 \\
& 5 & 393.86 & 330.41 & 391.14 & 376.48 & 397.54 & 400.62 \\
& 10 & 270.21 & 234.42 & 268.12 & 255.34 & 231.26 & 221.16 \\
& 15 & 201.17 & 186.59 & 198.10 & 188.73 & 184.55 & 175.44 \\
& 20 & 164.99 & 163.09 & 164.20 & 155.98 & 160.89 & 152.13 \\
\hline
\end{tabular}

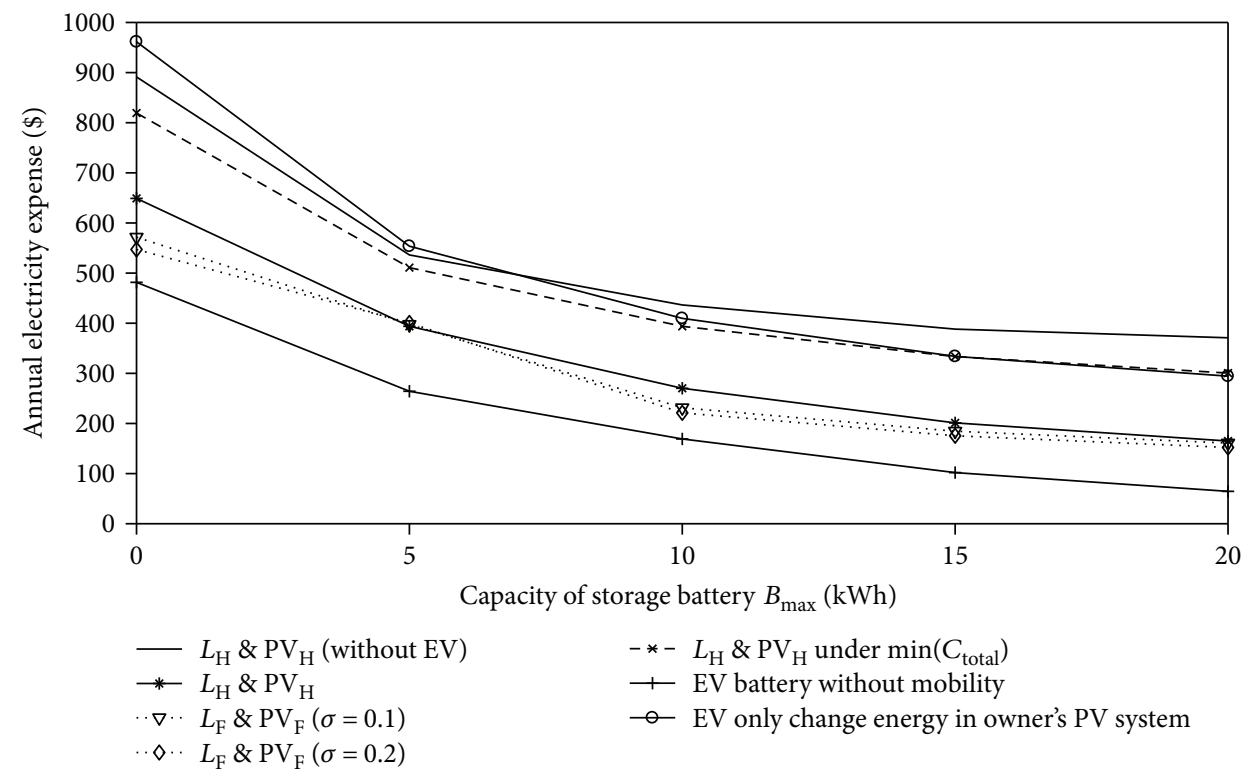

FIgURE 3: Change of annual consumption on electricity with varied available storage battery capacity.

TABLE 4: Results of annual electricity expense with $B_{\max }=5 \mathrm{kWh}$ and $\min \left(C_{i}\right)$ under different $\sigma$ of forecasting PV model.

\begin{tabular}{lcccccc}
\hline Assumed $\sigma$ in PV prediction model & 0.01 & 0.05 & 0.1 & 0.2 & 0.5 & 1 \\
Annual electricity expense under the objective function $\min \left(C_{i}\right)$ & 393.86 & 394.77 & 397.54 & 400.62 & 399.54 & 2.41 \\
\hline
\end{tabular}

ahead optimal control strategies with different objective functions; one is minimizing the daily electricity expense of individual distributed PV system and the other is minimizing the daily total expense of distributed PV systems which EV can be connected to. The control structure makes the customer obtain a lowest expense on electricity through the storage battery system control in the first level by geometrical logic analysis methodology and EV optimal scheduling control with multiple-mode application in the second level. The model has been verified and analyzed by the actual historical data and forecast data, respectively. The results show that if the distributed PV system only with the storage battery and without EV application is being used, the electricity expense can obtain a reduction from $13.44 \%$ to $58.39 \%$ with the battery capacity increasing from $1 \mathrm{kWh}$ to $20 \mathrm{kWh}$. If the distributed PV system without storage battery and with EV application is being used, the electricity expense can obtain a reduction of $27.18 \%$. Furthermore, when the distributed $\mathrm{PV}$ system with the storage battery increases as well as EV application, the electricity expense can obtain a reduction from $30.67 \%$ to $81.49 \%$. Under the total objective, the total expense and even the individual expense have different degrees of reduction. However, the specific benefits should rerationally distributed by balancing the interests of all distributed PV systems. Besides economic consideration, the models explained in this article can be easily introduced into the environment and energy conservation goals. In addition, this model may have some potential on the development of regional energy system. Future work will focus on further improving the performance of $\mathrm{PV}$ generation forecast model and the electricity demand forecast model and supplementing reasonable real-time control strategy to obtain a higher benefit.

\section{Nomenclature}

$E_{\mathrm{PV}}$ : The forecasting PV output in unit time interval $V_{\mathrm{OC}}: \quad$ The open-circuit voltage $(\mathrm{V})$

$I_{\mathrm{SC}}: \quad$ The short-circuit current (A) 


\begin{tabular}{|c|c|}
\hline$V_{\mathrm{M}}:$ & The voltage at maximum power point $(\mathrm{V})$ \\
\hline$I_{\mathrm{M}}:$ & The current at maximum power point (A) \\
\hline$N:$ & The serial number of PV cells in one panel \\
\hline$N_{s}:$ & The serial number of PV array \\
\hline$N_{\mathrm{p}}:$ & The parallel number of PV array \\
\hline$G:$ & The solar irradiance $\left(\mathrm{kW} / \mathrm{m}^{2}\right)$ \\
\hline Temp: & The temperature $\left({ }^{\circ} \mathrm{C}\right)$ \\
\hline$t_{\text {in }}:$ & Unit time interval, which is $30 \mathrm{~min}$ in this paper \\
\hline $\mathrm{Er}_{\mathrm{PV}}:$ & $\begin{array}{l}\text { The error between the PV forecasting value and } \\
\text { the actual PV generation }(\mathrm{kWh})\end{array}$ \\
\hline$\widehat{E_{\mathrm{PV}}}:$ & The forecasting PV value (kWh) \\
\hline$E_{\mathrm{PV}}:$ & The actual PV generation (kWh) \\
\hline$\mu:$ & The mean error \\
\hline$\sigma:$ & Mean square deviation \\
\hline $\mathbf{V}_{I}$ : & $\begin{array}{l}\text { Vectors of inputs in BNN load forecasting } \\
\text { model }\end{array}$ \\
\hline t: & Time of every day \\
\hline $\mathbf{d}_{\mathrm{t}}$ : & Day type \\
\hline T: & Ambient temperature $\left({ }^{\circ} \mathrm{C}\right)$ \\
\hline RH: & Relative humidity (\%) \\
\hline$n:$ & $\begin{array}{l}\text { The series order number of historical sample } \\
\text { data's intervals }\end{array}$ \\
\hline L: & Historical load data $(\mathrm{kWh})$ \\
\hline$E_{\mathrm{B}}:$ & The battery energy change (kWh) \\
\hline$E_{\mathrm{B}_{+}}:$ & The charging energy $(\mathrm{kWh})$ \\
\hline$E_{\mathrm{B}_{-}}:$ & The discharging energy $(\mathrm{kWh})$ \\
\hline$P_{\mathrm{B}_{\text {max }_{\text {charge }}}:}:$ & The maximum charging rates of battery $(\mathrm{kW} / \mathrm{h})$ \\
\hline$P_{\mathrm{B}_{\text {max }} \text { discharge }}:$ & $\begin{array}{l}\text { The maximum discharging rates of battery } \\
(\mathrm{kW} / \mathrm{h})\end{array}$ \\
\hline$E_{\mathrm{B}_{\text {size }}}:$ & $\begin{array}{l}\text { The specified capacity of the storage battery } \\
(\mathrm{kWh})\end{array}$ \\
\hline$E_{\mathrm{B}_{0}}:$ & The initial battery energy (kWh) \\
\hline SoC $_{\mathrm{B}_{\min }}$ : & The minimum SoC of battery \\
\hline SoC $B_{\max }:$ & The maximum SoC of battery \\
\hline$E_{\mathrm{B}_{\text {loss }}}:$ & The energy loss of the battery (kWh) \\
\hline $\mathrm{B}_{\text {size }}$ : & The capacity of the storage battery (kWh) \\
\hline$B_{\max }:$ & $\begin{array}{l}\text { The maximum energy could be used in the } \\
\text { storage battery when it is fully charged (kWh) }\end{array}$ \\
\hline$E_{\mathrm{EV}}:$ & The battery energy change of EV battery (kWh) \\
\hline$E_{\mathrm{EV}_{+}}:$ & The energy change by G2V mode (kWh) \\
\hline$E_{\mathrm{EV}_{-}}:$ & The energy export by V2G mode (kWh) \\
\hline$P_{\mathrm{EV}_{\text {max }_{\text {charge }}}}:$ & $\begin{array}{l}\text { The maximum charging rate of the EV battery } \\
(\mathrm{kW} / \mathrm{h})\end{array}$ \\
\hline$P_{\mathrm{EV}_{\text {max }_{\text {discharge }}}:}$ & $\begin{array}{l}\text { The maximum discharging rate of the EV } \\
\text { battery }(\mathrm{kW} / \mathrm{h})\end{array}$ \\
\hline$E_{\mathrm{EV}_{0}}:$ & The initial state of battery (kWh) \\
\hline SoC $\mathrm{EV}_{\min }$ : & The minimum SoC of EV battery \\
\hline SoC $\mathrm{EV}_{\max }$ : & The maximum SoC of EV battery \\
\hline$E_{\mathrm{EV}_{\text {loss }}}:$ & The energy loss of the EV battery (kWh) \\
\hline$E_{\text {trip }}:$ & $\begin{array}{l}\text { The energy consumed when the EV is driving } \\
\text { on a certain trip between two known locations } \\
\text { within some time }(\mathrm{kWh})\end{array}$ \\
\hline$C_{\mathrm{a}}:$ & The annual cost of V2G (\$) \\
\hline$E_{\mathrm{V} 2 \mathrm{G}}:$ & $\begin{array}{l}\text { The energy available in each EV per dispatch } \\
(\mathrm{kWh})\end{array}$ \\
\hline$N_{\mathrm{d}}:$ & The number of dispatches per year \\
\hline
\end{tabular}

$\begin{array}{ll}C_{\mathrm{d}}: & \text { The cost of battery degradation }(\$) \\ r_{\mathrm{e}}: & \text { The electricity price }(\$ / \mathrm{kWh}) \\ k: & \text { The number of distributed PV systems } \\ i: & \text { The ordered distributed PV systems in which } \\ & \text { the EV battery is being connected to its power } \\ & \text { grid in time } t \\ j: & \text { The other ordered distributed PV systems } \\ & \text { without EV connection in time } t \\ n_{\mathrm{f}}: & \text { The final time order } \\ t: & \text { The ordered period with observation time } \\ C_{i}: & \text { interval } t_{\text {in }} \\ C_{\mathrm{total}}: & \text { The minimizing electricity cost of one specific } \\ & \text { distributed PV system }(\$) \\ & \text { The minimization of the total electricity costs } \\ L_{\mathrm{H}}: & \text { for all the distributed PV systems which an EV } \\ \mathrm{PV}_{\mathrm{H}}: & \text { battery may participate in }(\$) \\ L_{\mathrm{F}}: & \text { The historical data of load } \\ \mathrm{PV}_{\mathrm{F}}: & \text { The historical data of PV generation }\end{array}$

\section{Conflicts of Interest}

The authors declare that they have no conflicts of interest.

\section{Acknowledgments}

The authors would like to thank Ausgrid, the Australian Bureau of Meteorology, and the Smart Grid Smart City project for the data applied in this paper. This work was supported by the National Natural Science Foundation of China (Grant No. 51478258, 51405287), Shanghai Committee of Science and Technology (Grant No. 18030501300).

\section{References}

[1] W. Shengjun, X. Qingshan, L. Qun, Y. Xiaodong, and C. Bing, "Optimal EV charging control strategy based on DC microgrid," Energy Procedia, vol. 100, pp. 243-247, 2016.

[2] C. Chen and S. Duan, "Optimal integration of plug-in hybrid electric vehicles in microgrids," IEEE Transactions on Industrial Informatics, vol. 10, no. 3, pp. 1917-1926, 2014.

[3] M. S. ElNozahy, T. K. Abdel-Galil, and M. M. A. Salama, "Probabilistic ESS sizing and scheduling for improved integration of PHEVs and PV systems in residential distribution systems," Electric Power Systems Research, vol. 125, pp. 55-66, 2015.

[4] Y. Guo, J. Xiong, S. Xu, and W. Su, "Two-stage economic operation of microgrid-like electric vehicle parking deck," IEEE Transactions on Smart Grid, vol. 7, no. 3, pp. 1703-1712, 2016.

[5] Y. Tang, J. Yang, J. Yan, and H. He, "Intelligent load frequency controller using GrADP for island smart grid with electric vehicles and renewable resources," Neurocomputing, vol. 170, pp. 406-416, 2015.

[6] S. Hashemi, J. Ostergaard, and G. Yang, "A scenario-based approach for energy storage capacity determination in LV grids with high PV penetration," IEEE Transactions on Smart Grid, vol. 5, no. 3, pp. 1514-1522, 2014.

[7] N. G. Paterakis, O. Erdinc, A. G. Bakirtzis, and J. P. S. Catalao, "Optimal household appliances scheduling under day-ahead 
pricing and load-shaping demand response strategies," IEEE Transactions on Industrial Informatics, vol. 11, no. 6, pp. 1509-1519, 2015.

[8] T. Kaschub, P. Jochem, and W. Fichtner, "Solar energy storage in German households: profitability, load changes and flexibility," Energy Policy, vol. 98, pp. 520-532, 2016.

[9] S. Cao, "Comparison of the energy and environmental impact by integrating a $\mathrm{H}_{2}$ vehicle and an electric vehicle into a zeroenergy building," Energy Conversion and Management, vol. 123, pp. 153-173, 2016.

[10] S. I. Kampezidou, E. Polymeneas, and S. Meliopoulos, "The economic effect of storage in systems with high penetration of renewable sources," in 2015 North American Power Symposium (NAPS), pp. 1-6, Charlotte, NC, USA, 2015.

[11] A. Assuncao, P. S. Moura, and A. T. de Almeida, "Technical and economic assessment of the secondary use of repurposed electric vehicle batteries in the residential sector to support solar energy," Applied Energy, vol. 181, pp. 120-131, 2016.

[12] F. Marra, G. Y. Yang, Y. T. Fawzy et al., "Improvement of local voltage in feeders with photovoltaic using electric vehicles," IEEE Transactions on Power Systems, vol. 28, no. 3, pp. 35153516, 2013.

[13] M. Honarmand, A. Zakariazadeh, and S. Jadid, "Self-scheduling of electric vehicles in an intelligent parking lot using stochastic optimization," Journal of the Franklin Institute, vol. 352, no. 2, pp. 449-467, 2015.

[14] S. Y. Derakhshandeh, A. S. Masoum, S. Deilami, M. A. S. Masoum, and M. E. Hamedani Golshan, "Coordination of generation scheduling with PEVs charging in industrial microgrids," IEEE Transactions on Power Systems, vol. 28, no. 3, pp. 3451-3461, 2013.

[15] H. O. R. Howlader, H. Matayoshi, and T. Senjyu, "Distributed generation incorporated with the thermal generation for optimum operation of a smart grid considering forecast error," Energy Conversion and Management, vol. 96, pp. 303-314, 2015.

[16] Z. Liu, C. Chen, and J. Yuan, "Hybrid energy scheduling in a renewable micro grid," Applied Sciences, vol. 5, no. 3, pp. 516-531, 2015.

[17] L. Ju, Z. Tan, J. Yuan, Q. Tan, H. Li, and F. Dong, “A bi-level stochastic scheduling optimization model for a virtual power plant connected to a wind-photovoltaic-energy storage system considering the uncertainty and demand response," Applied Energy, vol. 171, pp. 184-199, 2016.

[18] L. Ju, H. Li, J. Zhao, K. Chen, Q. Tan, and Z. Tan, "Multiobjective stochastic scheduling optimization model for connecting a virtual power plant to wind-photovoltaic-electric vehicles considering uncertainties and demand response," Energy Conversion and Management, vol. 128, pp. 160-177, 2016.

[19] V. N. Coelho, I. M. Coelho, B. N. Coelho et al., "Multi-objective energy storage power dispatching using plug-in vehicles in a smart-microgrid," Renewable Energy, vol. 89, pp. 730$742,2016$.

[20] L. B. Jaramillo and A. Weidlich, "Optimal microgrid scheduling with peak load reduction involving an electrolyzer and flexible loads," Applied Energy, vol. 169, pp. 857-865, 2016.

[21] F. Gao, W. Tang, T. Yan et al., "Day-ahead energy optimal scheduling of household microgrid considering the user satisfaction," 2015 IEEE PES Asia-Pacific Power and Energy
Engineering Conference (APPEEC), 2015, pp. 1-5, Brisbane, QLD, Australia, 2015.

[22] J. Zhao, S. Kucuksari, E. Mazhari, and Y.-J. Son, "Integrated analysis of high-penetration PV and PHEV with energy storage and demand response," Applied Energy, vol. 112, pp. 3551, 2013.

[23] S. Bracco, F. Delfino, F. Pampararo, M. Robba, and M. Rossi, "A dynamic optimization-based architecture for polygeneration microgrids with tri-generation, renewables, storage systems and electrical vehicles," Energy Conversion and Management, vol. 96, pp. 511-520, 2015.

[24] J. A. Gow and C. D. Manning, "Development of a photovoltaic array model for use in power-electronics simulation studies," IEE Proceedings - Electric Power Applications, vol. 146, no. 2, pp. 193-200, 1999.

[25] G. R. Walker, "Evaluating MPPT converter topologies using a Matlab PV Model," Journal of Electrical \& Electronics Engineering Australia, vol. 21, no. 1, pp. 49-55, 2001.

[26] Q. Zhong, R. Khalilpour, A. Vassallo, and Y. Sun, "A logic-based geometrical model for the next day operation of PV-battery systems," Journal of Energy Storage, vol. 7, pp. 181-194, 2016.

[27] C. Zhou, K. Qian, M. Allan, and W. Zhou, "Modeling of the cost of EV battery wear due to V2G application in power systems," IEEE Transactions on Energy Conversion, vol. 26, no. 4, pp. 1041-1050, 2011.

[28] "Solar home electricity data notes. Sydney: Ausgrid," https:// www.ausgrid.com.au/Common/About-us/Corporate-information/Data-to-share/Solar-home-electricity-data.aspx.

[29] "Research and Markets: Australia-Smart Grid-Smart City Project-2011,” https://trove.nla.gov.au/work/160745433?q\&version $\mathrm{Id}=175242047$. 


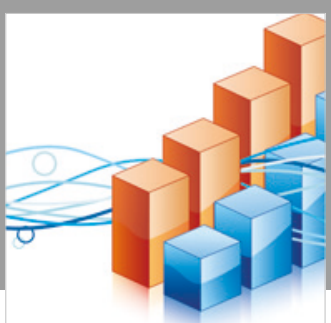

Advances in

Operations Research

\section{-n-m}
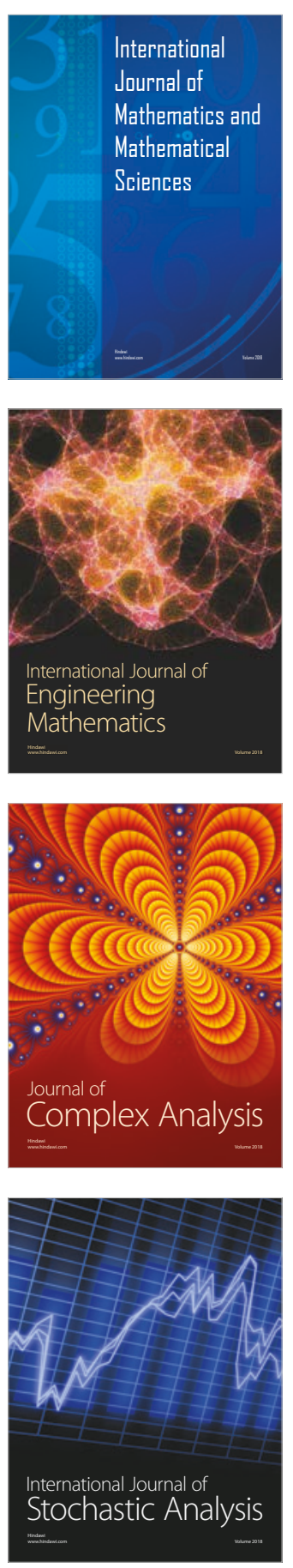
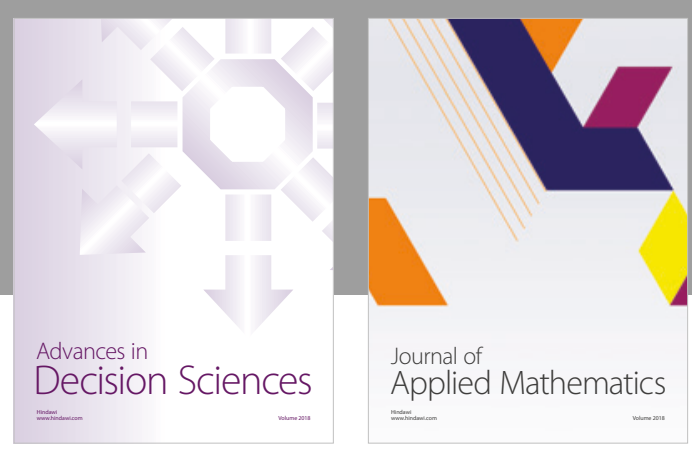

Journal of

Applied Mathematics
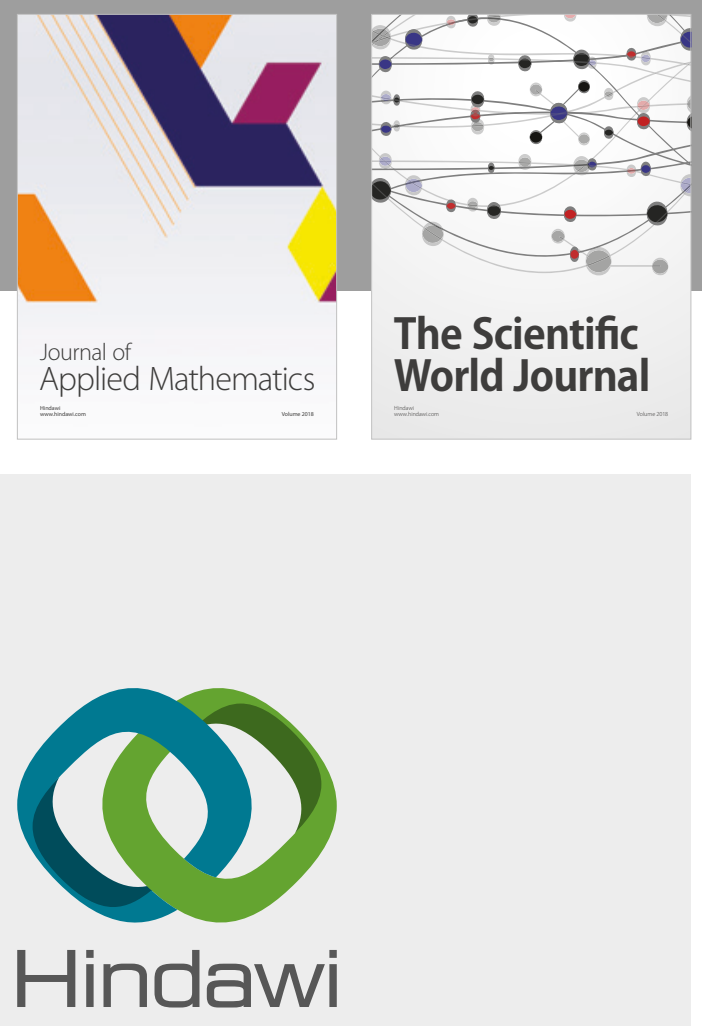

Submit your manuscripts at

www.hindawi.com

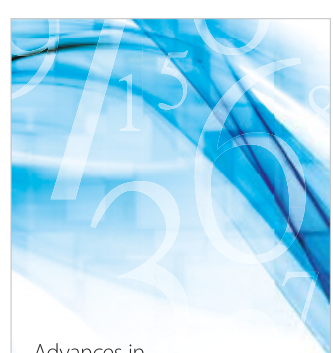

Advances in
Numerical Analysis
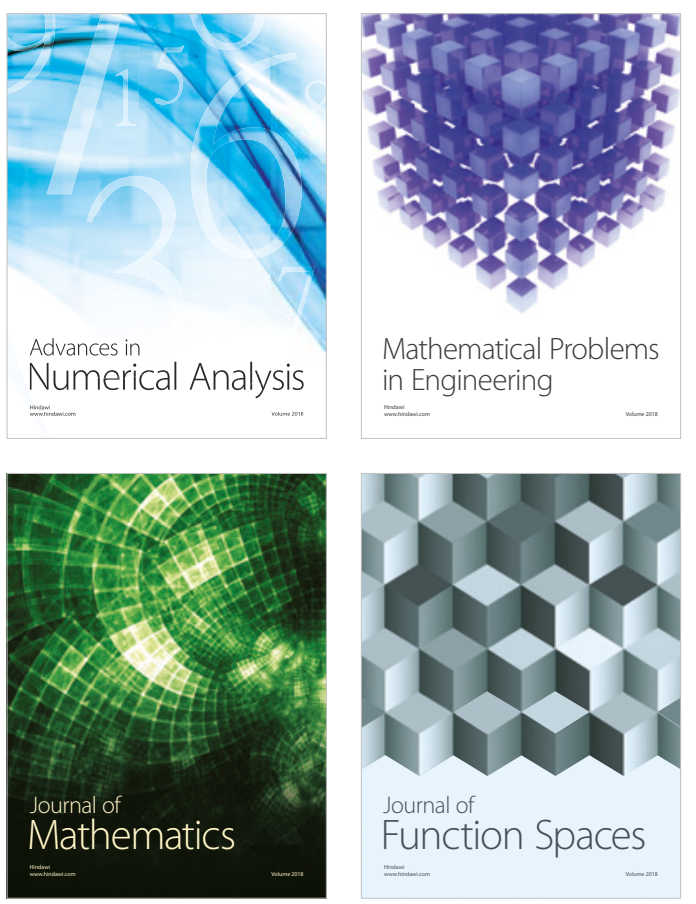

Mathematical Problems in Engineering

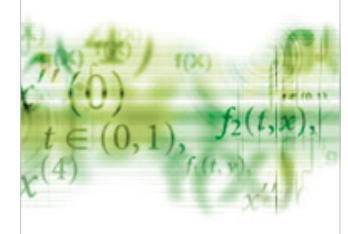

International Journal of

Differential Equations

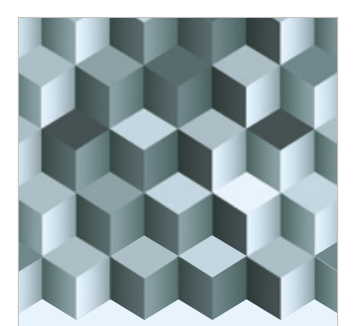

Journal of

Function Spaces
The Scientific

World Journal

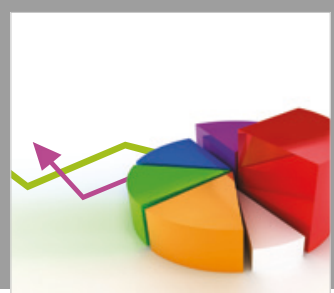

Journal of

Probability and Statistics
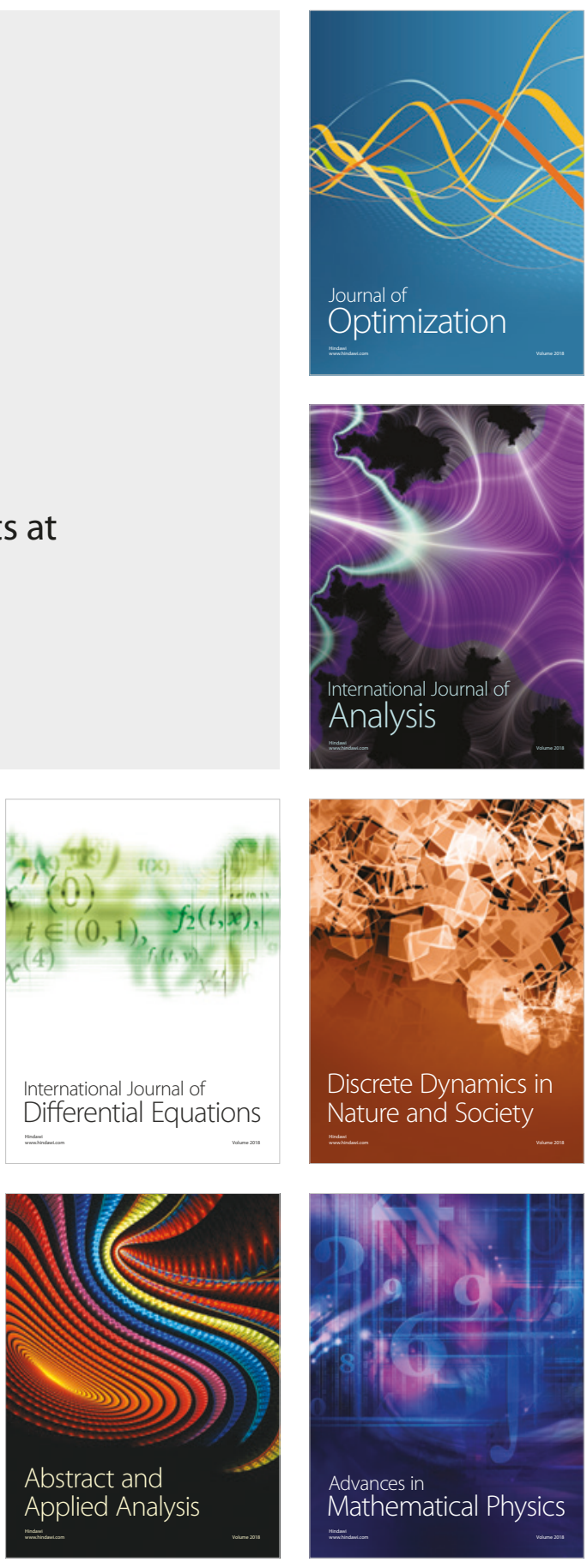